\title{
Tau deletion impairs intracellular $\beta$-amyloid-42 clearance and leads to more extracellular plaque deposition in gene transfer models
}

\author{
Irina Lonskaya ${ }^{1}$, Michaeline Hebron ${ }^{1}$, Wenqiang Chen ${ }^{1,2}$, Joel Schachter ${ }^{3}$ and Charbel Moussa ${ }^{1 *}$
}

\begin{abstract}
Background: Tau is an axonal protein that binds to and regulates microtubule function. Hyper-phosphorylation of Tau reduces its binding to microtubules and it is associated with $\beta$-amyloid deposition in Alzheimer's disease. Paradoxically, Tau reduction may prevent $\beta$-amyloid pathology, raising the possibility that Tau mediates intracellular A $\beta$ clearance. The current studies investigated the role of Tau in autophagic and proteasomal intracellular A $1-42$ clearance and the subsequent effect on plaque deposition.

Results: Tau deletion impaired $A \beta$ clearance via autophagy, but not the proteasome, while introduction of wild type human Tau into $\mathrm{Tau}^{-1-}$ mice partially restored autophagic clearance of A $\beta 1-42$, suggesting that exogenous Tau expression can support autophagic A $1-42$ clearance. Tau deletion impaired autophagic flux and resulted in $A \beta 1-42$ accumulation in pre-lysosomal autophagic vacuoles, affecting A $\beta 1-42$ deposition into the lysosome. This autophagic defect was associated with decreased intracellular A $\beta 1-42$ and increased plaque load in $\mathrm{Tau}^{-1-}$ mice, which displayed less cell death. Nilotinib, an Abl tyrosine kinase inhibitor that promotes autophagic clearance mechanisms, reduced AB1-42 only when exogenous human Tau was expressed in $\mathrm{Tau}^{-1-}$ mice.
\end{abstract}

Conclusions: These studies demonstrate that Tau deletion affects intracellular A $\beta 1-42$ clearance, leading to extracellular plaque.

Keywords: Tau, Intracellular Aß1-42, Plaques, Autophagy, Proteasome

\section{Background}

Two major pathologies that are linked to Alzheimer's disease $(A D)$, include extracellular $\beta$-amyloid $(A \beta)$ plaques and intracellular neurofibrillary tangles (NFTs) comprised of hyper-phosphorylated Tau (p-Tau) [1]. Although A $\beta$ peptides initially appeared to act upstream of Tau pathology in $\mathrm{AD}[2,3]$, more recent data suggest that Tau mediates $A \beta$ toxicity since reduction of endogenous Tau levels attenuates $A \beta$-induced neurodegeneration $[4,5]$. Tau may be a critical mediator of $A \beta$ toxicity in $A D[6,7]$. The level of insoluble $\mathrm{p}$-Tau accumulation positively correlates with neurodegeneration and cognitive decline [8], suggesting that Tau dysfunction underlies dementia [9]. Interestingly, some aged human brains develop plaques

\footnotetext{
* Correspondence: cem46@georgetown.edu

'Department of Neuroscience, Laboratory for Dementia and Parkinsonism, Georgetown University Medical Center, 3970 Reservoir RD, Washington, DC 20057, USA

Full list of author information is available at the end of the article
}

with no dementia or major cognitive decline $[10,11]$, while neocortical and hippocampal $A \beta$ and Tau together are often associated with dementia [12]. However, Tau mutations or modifications are causal to some neurodegenerative diseases without plaques, including fronto-temporal dementia linked to chromosome 17 with Parkinsonism (FTDP-17), progressive supranuclear palsy (PSP), and corticobasal degeneration (CBD), suggesting Tau associated neurodegeneration without $A \beta$ deposition [6,7]. Taken together these findings suggest that Tau is a critical regulator of $A \beta 1-42$ toxicity through clearance of toxic intracellular $A \beta 1-42$ [13] and modulation of extracellular plaque deposition, thus counteracting the toxic effects of $A \beta 1-42$. The interplay between $A \beta$ and Tau suggests that Tau mediates the development and progression of neurodegeneration or it modulates $A \beta$ clearance and contributes to protection.

To evaluate whether Tau function affects intracellular $A \beta$ clearance and alters extracellular plaque formation, we used 
lentiviral gene transfer models to focus on intracellular A $\beta 1-42$ clearance in wild type and $\mathrm{Tau}^{-1-}$ mice. Intracellular $\mathrm{A} \beta$ may be cleared via autophagy and/or the proteasome $[14,15]$. We previously demonstrated that lentiviral A $\beta 1-42$ expression leads to p-Tau accumulation and inhibition of both the proteasome and autophagy [13,14,16,17], while the Abl tyrosine kinase inhibitor Nilotinib increases autophagic $A \beta$ and $p$-Tau clearance, leading to decreased plaque levels in AD models $[14,16]$. Here we present evidence in primary hippocampal neurons and in mouse brain that Tau expression is critical for autophagic amyloid clearance. Our data suggest that Tau deletion inhibits autophagic flux, resulting in reduction of intracellular $A \beta$ degradation and increased plaque deposition.

\section{Results and discussion}

\section{Autophagy and the proteasome contribute to $\mathrm{p}$-Tau and} A $\beta$ 1-42 clearance

We previously demonstrated that impaired autophagic clearance of intracellular $A \beta$ leads to more plaque deposition in parkin deficient mice $[13,14,16,17]$. To determine the contribution of autophagic and proteasomal A $\beta 1-42$ clearance with and without Tau over-expression, primary neuronal hippocampus cultures were infected after 14 days in vitro (DIV) with lentiviral constructs driving the expression of human A $\beta 1-42$ or wild type (WT) human Tau for 24 hrs. We previously showed that Nilotinib promotes autophagic clearance of A $\beta 1-42$ [14,18]. To selectively enhance autophagic protein clearance, neurons were treated with $10 \mu \mathrm{M}$ Nilotinib (or $1 \mu \mathrm{L}$ DMSO) for $24 \mathrm{hrs}$ (all cells were treated with DMSO unless Nilotinib was present). To inhibit autophagy, neurons were treated with $100 \mathrm{nM}$ Bafilomycin-A1, and to block the proteasome neurons were treated with $20 \mu \mathrm{M} \mathrm{MG132}$ for $6 \mathrm{hrs}$. As expected, Nilotinib significantly decreased human A $\beta 1-42$ levels (Figure $1 \mathrm{~A}, \mathrm{n}=5, \mathrm{p}<0.04$ ) compared to DMSO $(1 \mu \mathrm{L})$. Nilotinib also significantly decreased $A \beta 1-42$ levels (Figure 1A, p < 0.05) when Tau was co-expressed with A $\beta 1-42$. No human (or mouse) A $\beta 1-42$ was observed when Tau was expressed alone. MG132 significantly increased $A \beta 1-42(n=5, p<0.043)$ compared to DMSO in neurons expressing lentiviral $A \beta 1-42$, indicating that some $A \beta 1-42$ is cleared via the proteasome. The combination of Nilotinib and MG132 significantly reduced A $\beta 1-42$ compared to MG132 alone $(\mathrm{p}<0.031)$, indicating that $A \beta 1-42$ may be cleared via autophagy and/or the proteasome. Nilotinib did not change A $\beta 1-42$ levels in neurons coexpressing Tau and A $1-42$ in the presence of MG132, but under these conditions (MG132 and Tau) A $\beta 1-42$ was significantly lower than MG132 ( $<<0.03)$. Bafilomycin-A1 significantly increased $A \beta 1-42(\mathrm{n}=5, \mathrm{p}<0.045)$ compared to DMSO. In the presence of Bafilomycin-A1, Nilotinib was unable to lower $A \beta 1-42$ levels, further indicating that A $\beta 1-42$ is partially cleared through autophagy.
We previously reported that lentiviral $A \beta 1-42$ expression leads to elevation of $\mathrm{p}$-Tau in the rat cortex $[13,14]$. To determine whether autophagic blockade and/or proteasomal inhibition affect amyloid secretion, we measured A $\beta 1-42$ and/or Tau in cell extracts (STEN buffer) and media. Lentiviral expression of human $A \beta 1-42$ in primary mouse hippocampal neurons led to a significant increase in soluble and secreted (media) A $\beta 1-42$ (Figure $1 \mathrm{~B}, \mathrm{p}<0.001$, $\mathrm{n}=5)$ at 24 hrs compared to $12 \mathrm{hrs}$ post-infection. Prolonged expression of lentiviral $A \beta 1-42$ for 48 hrs resulted in lower levels of soluble and media $A \beta 1-42$ compared to 24 hrs, but remained higher than 12 hrs $(\mathrm{p}<0.01)$. The level of Ser 396 p-Tau was increased (Figure 1C, p $<0.001$, $\mathrm{n}=5$ ) with a concomitant increase in media $\mathrm{p}$-Tau (Figure $1 \mathrm{C}, \mathrm{p}<0.05, \mathrm{n}=5$ ) when $\mathrm{A} \beta 1-42$ was expressed for $24 \mathrm{hrs}$ compared to $12 \mathrm{hrs}$, indicating that $A \beta 1-42$ expression triggers murine $\mathrm{p}$-Tau. $\mathrm{p}$-Tau levels were further increased $(\mathrm{p}<0.0001, \mathrm{n}=5)$ at $48 \mathrm{hrs}$, suggesting progressive accumulation of $\mathrm{p}$-Tau in response to A $\beta 1-42$.

Because of the observed effects of $A \beta 1-42$ on p-Tau, we also measured $\mathrm{p}$-Tau in cell extracts via ELISA in parallel with $A \beta 1-42$ as shown in Figure 1A. Nilotinib prevented $\mathrm{A} \beta 1$-42-induced $\mathrm{p}$-Tau (Figure 1D, $\mathrm{n}=5, \mathrm{p}<0.03$ ) compared to DMSO $(1 \mu \mathrm{L})$. Lentiviral expression of human WT Tau and A $\beta 1-42$ together (DMSO) increased p-Tau (Figure $1 \mathrm{D}, \mathrm{n}=5, \mathrm{p}<0.03$ ) compared to $\mathrm{A} \beta 1-42$ alone but Nilotinib reversed $\mathrm{p}$-Tau (Figure $1 \mathrm{D}, \mathrm{p}<0.04$ ) back to the level of $A \beta 1-42$ expression alone.

Proteasome inhibition (MG132) increased p-Tau in LacZ infected cells (Figure 1D, $n=5, p<0.05$ ) or in the presence of A $1-42$ (+DMSO). However, Nilotinib prevented $\mathrm{p}$-Tau accumulation even in the presence of MG132 in A $\beta 1-42$ expressing cells $(n=5, p<0.036)$. Nilotinib also reduced $\mathrm{p}$-Tau (Figure 1D, $\mathrm{n}=5, \mathrm{p}<0.03$ ) in cells co-expressing Tau and A $\beta 1-42$ together, further suggesting that autophagy co-operates with the proteasome to clear p-Tau. MG132 significantly increased p-Tau in Tau expressing cells $(\mathrm{p}<0.001)$.

Bafilomycin-A1 robustly increased p-Tau in A $\beta 1-42$ (+DMSO) infected cells (Figure 1D, $\mathrm{n}=5, \mathrm{p}<0.034$ ) and Nilotinib had no effect on p-Tau with Bafilomycin-A1. Lentiviral expression was verified by Western blots (WB) showing equal levels of V5 lentiviral tag (Figure 1D insert, $1^{\text {st }}$ blot) in cells expressing lentiviral human $A \beta 1-42$ ( $2^{\text {nd }}$ blot $)$ or human Tau ( $3^{\text {rd }}$ blot $)$ compared to total Tau levels $\left(4^{\text {th }}\right.$ blot) relative to actin $\left(5^{\text {th }}\right.$ blot). The ELISA results of Tau metabolism were confirmed with WB using AT8 antibody (Figure $1 \mathrm{E}, \mathrm{n}=4$ ). Tau or $\mathrm{A} \beta$ significantly $(\mathrm{p}<0.05)$ increased $\mathrm{p}$-Tau compared to LacZ ( $1^{\text {st }}$ blot) or in the presence of MG132 ( $3^{\text {rd }}$ blot) or Bafilomycin-A1 ( $5^{\text {th }}$ blot) relative to actin. Nilotinib reduced $\mathrm{p}$-Tau relative to actin $\left(1^{\text {st }}\right.$ blot, $\left.\mathrm{p}<0.05\right)$ when $A \beta 1-42$ and Tau were expressed together or separately 


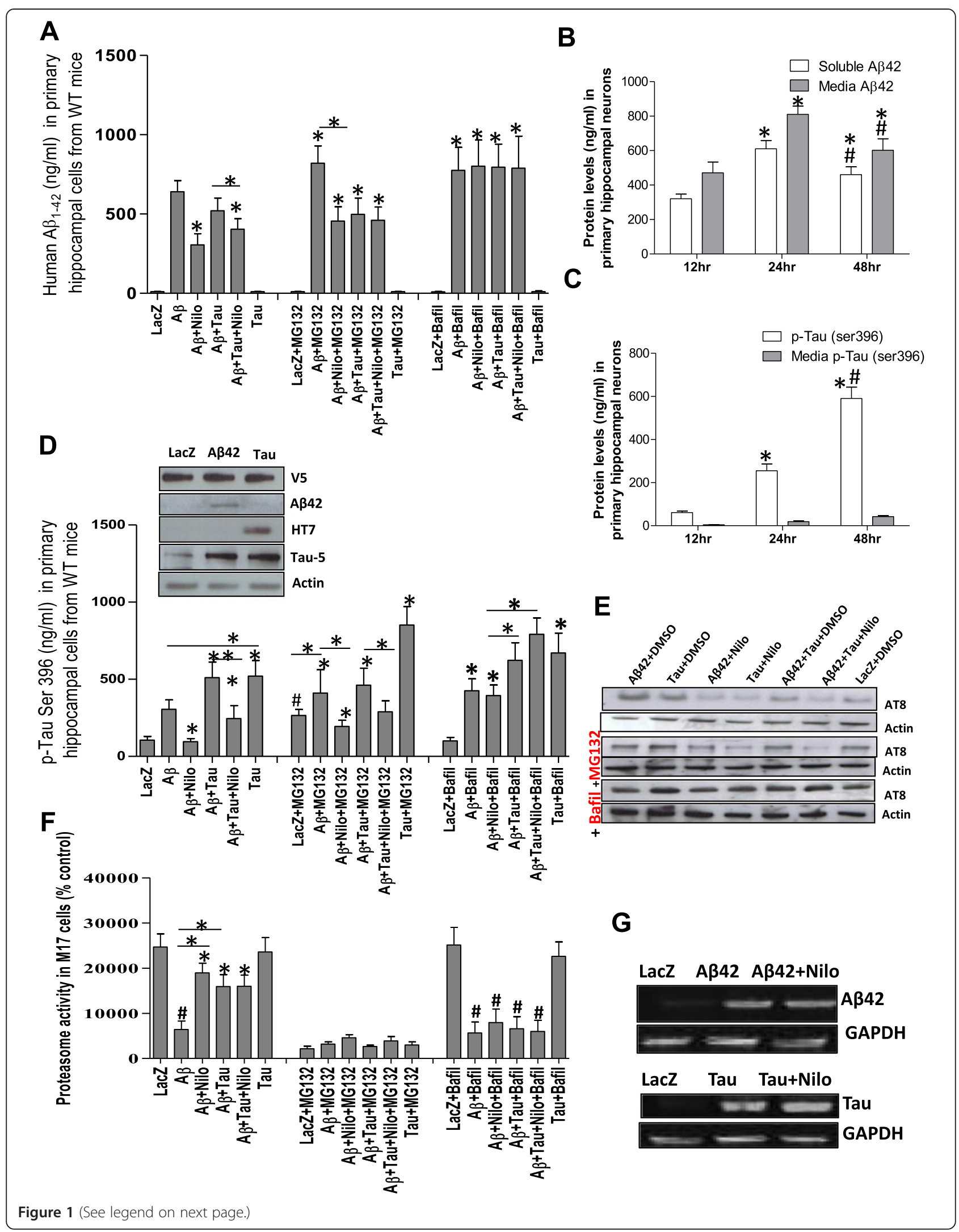


(See figure on previous page.)

Figure $\mathbf{1}$ Inhibition of the proteasome or autophagy partially affects $\mathbf{A} \boldsymbol{\beta} \mathbf{1 - 4 2}$ and $\mathbf{p}$-Tau clearance. To dissect out the contribution of the proteasome from autophagy-lysosome in amyloid clearance, primary hippocampal neurons (DIV14) were infected with lentivirus plasmids, and then treated with $1 \mu$ DMSO or autophagy modulators (Nilotinib or Bafilomycin-A1) and/or proteasome inhibitor (MG132). Histograms represent ELISA concentrations of $\mathbf{A})$ A 1-42 and time course showing the distribution of intracellular and media $\mathbf{B}$ ) A 1 1-42 and $\mathbf{C}$ ) p-Tau Ser 396. D) p-Tau Ser 396 in the presence of modulators of autophagy and the proteasome. Insert). WB analysis on 4-12\% NuPAGE SDS gel showing expression of the lentiviral tag V5, A 1 1-42, human Tau (HT7) and total Tau relative to actin. E) WB analysis on 10\% NuPAGE SDS gel showing AT8 levels relative to actin. F) Histograms represent $20 \mathrm{~S}$ proteasome activity assay in human M17 neuroblastoma cells. G) RT-PCR showing the effects of Nilotinib on lentiviral gene expression relative to GAPDH. \# indicates significantly different to LacZ, Asterisk is significantly different to Aß1-42 + DMSO or as indicated, bars are mean \pm SEM, two-way ANOVA.

in the presence or absence of MG132, while BafilomycinA1 blocked the effects of Nilotinib on $\mathrm{p}$-Tau reduction.

To further determine the effects of A $\beta 1-42$ and p-Tau on proteasome activity, a chymotrypsin-like assay in M17 neuroblastoma showed that A $\beta 1-42$ (with DMSO) significantly decreased proteasomal function (Figure $1 \mathrm{~F}$, $\mathrm{n}=6, \mathrm{p}<0.001$ ) compared to LacZ (DMSO), but Nilotinib partially reversed $A \beta 1-42$ effects on proteasome function $(\mathrm{p}<0.01)$ in cells expressing $\mathrm{A} \beta 1-42$ alone or together with Tau. Tau did not affect proteasomal function, but Tau and $A \beta 1-42$ together significantly reduced proteasome activity ( $\mathrm{p}<0.04$ ) compared to Tau or LacZ. MG132 completely inhibited the proteasome. However, BafilomycinA1 did not affect proteasomal activity in control (LacZ) or Tau expressing cells, but significantly decreased it in A $\beta 1-42$ expressing cells with and without Tau, further suggesting that lack of $A \beta 1-42$ clearance affects proteasome activity. The effects of Nilotinib on lentiviral human A $\beta 1-42$ and Tau expression were verified by RT-PCR using the same primers that were utilized to clone $A \beta 1-42$ and Tau into the lentivirus as we previously described $[13,15,19]$. Nilotinib did not affect $A \beta 1-42$ (Figure 1G, top blot) and Tau (Figure 1G, bottom blot) RNA levels compared to DMSO relative to GAPDH, suggesting that Nilotinib does not alter lentiviral expression.

\section{Tau is required for autophagic amyloid clearance}

To focus on the effects of Tau deletion on intracellular A $\beta 1-42$ clearance, we tested our model in WT and $\mathrm{Tau}^{-/-}$mouse primary hippocampal neurons in vitro. Mouse hippocampal neurons were prepared from C57BL/ 6 (WT) and homozygous $\mathrm{Tau}^{-/-}$mice $[20,21]$ and infected with the lentiviral clones at DIV14. Nilotinib reduced the levels of A $\beta 1-42$ in $\mathrm{Tau}^{-1-}$ neurons (compared to DMSO, $\mathrm{p}<0.047$ ) and in cells expressing $\mathrm{A} \beta 1-42$ and Tau together (Figure $2 \mathrm{~A}, \mathrm{n}=5, \mathrm{p}<0.032$ ). Interestingly, $\mathrm{A} \beta 1-42$ and Tau together (+DMSO) reduced A $\beta 1-42$ levels $(\mathrm{p}<0.042)$ compared to $\mathrm{A} \beta 1-42$ alone (+DMSO) and Nilotinib further decreased $A \beta 1-42$ (Figure $2 A, p<0.035$ ), suggesting that Tau expression partially increases $A \beta 1-42$ clearance. MG132 blocked Nilotinib-induced A $\beta 1-42$ clearance in $\mathrm{Tau}^{-/-}$neurons, but Tau expression reduced A $\beta 1-42$ levels $(\mathrm{p}<0.037)$. No $\mathrm{A} \beta 1-42$ was detected in Tau expressing $\mathrm{Tau}^{-/-}$primary neurons. Bafilomycin-A1 increased A $\beta 1$ -
42 levels $(\mathrm{p}<0.05)$ and Nilotinib did not reverse these effects in $\mathrm{Tau}^{-1-}$ neurons, but Tau expression reduced A 1 1-42 back to DMSO levels ( $\mathrm{p}<0.05)$, further suggesting that Tau expression enhances amyloid clearance. No p-Tau was detected in A $\beta 1-42$ expressing $\mathrm{Tau}^{-/-}$neurons, but Nilotinib significantly (Figure 2B, $\mathrm{n}=5, \mathrm{p}<0.05$ ) reduced $\mathrm{p}$-Tau compared to DMSO in Tau alone or with A 1 1-42. MG132 increased $p$-Tau levels $(\mathrm{p}<0.03)$ even in the presence of Nilotinib when Tau was expressed alone or together with A $\beta 1-42$. However, both MG132 and Bafilomycin-A1 blocked Nilotinib-induced p-Tau decrease $(\mathrm{p}<0.01)$ in the presence of Tau alone or together with A $\beta 1-42$. Together, these data suggest that Tau is required for complete amyloid clearance.

These results were also conducted in vivo in WT $(\mathrm{C} 57 \mathrm{BL} / 6)$ and $\mathrm{Tau}^{-1-}$ mice, which are relevant to our experiments because organelle movement was reported to be impaired in these mice [20,21], which my potentially affect autophagosome movement. Mice were stereotaxically injected into the hippocampus with V5-tagged lentiviral constructs driving human Tau and $A \beta 1-42$ expression and adjusted with LacZ to $1 \times 10^{6}$ multiplicity of infection (MOI). Animals were treated 3 weeks post-injection with daily $10 \mathrm{mg} / \mathrm{kg}$ intraperotineal (I.P) injection of Nilotinib or $30 \mu \mathrm{L}$ DMSO once a day for 3 (additional) consecutive weeks as we previously reported $[14,16]$. To verify equal expression of lentiviral clones, $20 \mu \mathrm{m}$ thick coronal brain sections were co-stained for human specific A $\beta 1-42$, p-Tau and V5 as shown in Additional file 1: Figure S1. No human (or mouse) A $\beta 1-42$ was detected by ELISA in human Tau expressing WT mice (Figure $2 \mathrm{C}, \mathrm{n}=4$ ), but Nilotinib reduced A $\beta 1-42$ levels when $A \beta 1-42$ was expressed alone $(\mathrm{p}<0.0001)$ or together with human Tau $(\mathrm{p}<0.001)$. Human A $\beta 1-42$ was significantly higher $(\mathrm{p}<0.01)$ in $\mathrm{A} \beta 1-42$ expressing $\mathrm{Tau}^{-/-}$mice compared to A $\beta 1-42$ expressing WT mice (Figure $2 \mathrm{C}, \mathrm{n}=4$ ). Nilotinib failed to reduce $A \beta 1-42$ levels in $\mathrm{Tau}^{-1-}$ mice compared to WT, but introduction of lentiviral human WT Tau with A $\beta 1-42$ into $\mathrm{Tau}^{-/-}$mice significantly reduced A $\beta 1-42$ $(\mathrm{p}<0.05)$ compared to $A \beta 1-42$ alone. These data suggest that exogenous human Tau facilitates autophagic A $\beta 1-42$ clearance. It is important to note that no changes were observed with mouse A $\beta 1-42$ when lentiviral human Tau or A $\beta 1-42$ were expressed in WT or $\mathrm{Tau}^{-1-}$ mice (data 
A

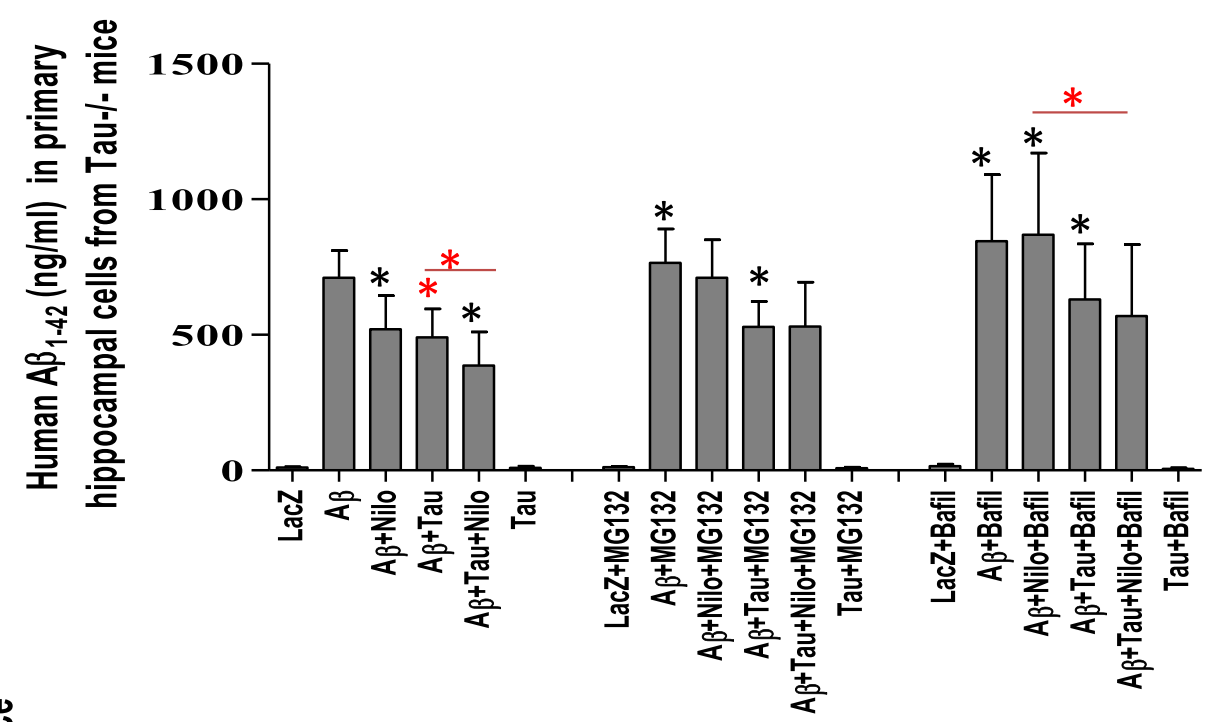

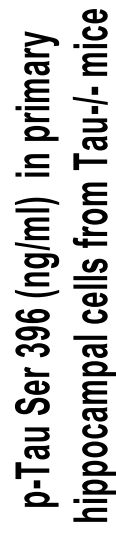
800
600
400
200
0

\section{C}

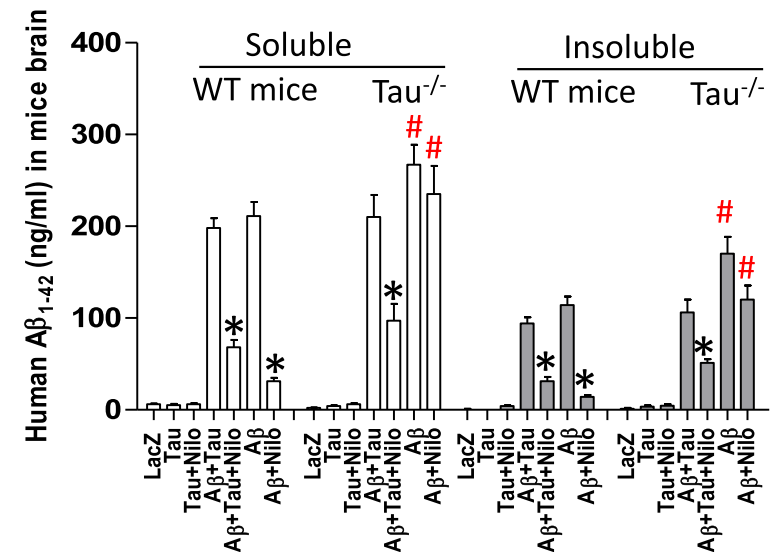

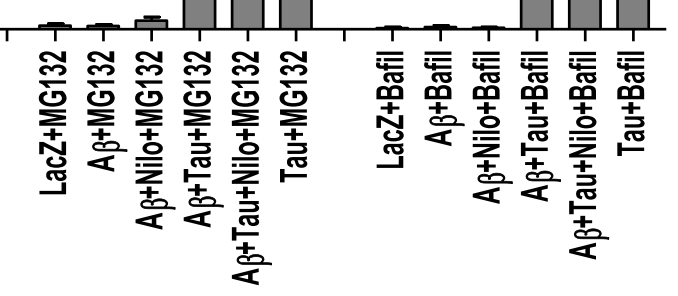

D

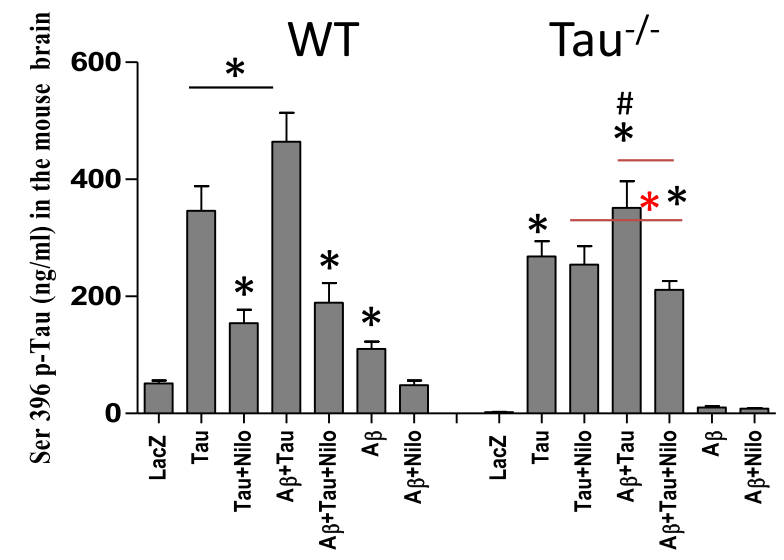

Figure $\mathbf{2}$ (See legend on next page.) 
(See figure on previous page.)

Figure 2 Tau deletion impairs autophagic clearance. Primary hippocampal neurons from WT and $\mathrm{Tau}^{-1-}$ mice were infected with lentivirus plasmids and then treated with $1 \mu$ I DMSO or autophagy modulators (Nilotinib or Bafilomycin-A1) and/or proteasome inhibitor (MG132). Histograms

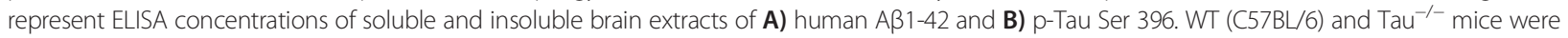
injected with $1 \times 10^{6}$ multiplicity of infection (MOI) of lentiviral human Tau, A $1-42$, Tau $\pm A \beta 1-42$ and adjusted with LacZ. All animals were treated 3 weeks post-injection with daily $10 \mathrm{mg} / \mathrm{kg}$ IP injection or $30 \mu \mathrm{L}$ DMSO once a day for 3 (additional) consecutive weeks. Histograms represent ELISA concentrations of total brain extracts of $\mathbf{C}$ ) human A $1-42$ and $\mathbf{D}$ ) p-Tau Ser 396. Asterisk is significantly different to A $1-42+$ DMSO or as indicated, \# indicates significantly different to A $1-42+$ DMSO in WT mice. Bars are mean \pm SEM, two-way ANOVA.

not shown), and no changes were detected in APP cleaving enzymes [14], indicating no changes in APP processing.

The effects of Nilotinib on p-Tau clearance were also examined. Nilotinib reduced $\mathrm{p}$-Tau (Figure 2D, $\mathrm{n}=4$, $\mathrm{p}<0.01)$ in Tau over-expressing WT mice and when Tau and $A \beta 1-42$ were expressed together $(p<0.015)$, which led to more $\mathrm{p}$-Tau than Tau alone $(\mathrm{p}<0.02)$. However, p-Tau was significantly lower (Figure 2D, $\mathrm{n}=4$, $\mathrm{p}<0.037)$ in human Tau expressing $\mathrm{Tau}^{-1-}$ compared to WT mice, and although A $\beta 1-42$ together with Tau significantly increased $\mathrm{p}$-Tau in $\mathrm{Tau}^{-/-}$mice $(\mathrm{p}<0.04)$, $\mathrm{p}$-Tau remained significantly lower $(\mathrm{p}<0.05)$ in $\mathrm{Tau}^{-/-}$compared to WT mice. Nilotinib did not change $\mathrm{p}$-Tau when human Tau was expressed alone in $\mathrm{Tau}^{-/-}$mice, but it significantly reduced it $(\mathrm{p}<0.03)$ when $\mathrm{A} \beta 1-42$ and Tau were co-expressed.

\section{Tau deletion impairs autophagic flux in mouse brain}

To determine autophagic flux, mouse brain tissues were fractionated to isolate autophagic vacuoles (AVs), which were identified by light chain protein-3 (LC3) that indicates pre-lysosomal autophagosome formation (Figure 3A, insert) as we previously indicated [14,16]. Lysosome associated membrane protein (LAMP)-2a was used as a marker of the lysosomal fraction (Figure 3A, n=4). Mitochondrial cytochrome c oxidase (COX)-IV was also used as another control marker. ELISA measurement of $A \beta 1-42$ in $A V s$ in WT mice expressing $A \beta 1-42$ showed $A \beta 1-42$ accumulation in AV10 (Figure $3 A, n=4$ ) and AV20 (Figure 3B, n $=4$ ) but not in the lysosome (Figure $3 C, n=4)$. Nilotinib significantly reduced $A \beta 1$ 42 in AV10 (Figure 3A, n $=4, \mathrm{p}<0.001$ ) and increased it in the lysosome (Figure $3 \mathrm{C}, \mathrm{p}<0.0001$ ), suggesting that Nilotinib facilitates autophagic flux from autophagosomal vacuoles to the lysosome [22]. In WT mice expressing $A \beta 1-42$ and Tau together, Nilotinib significantly reduced $\mathrm{A} \beta 1-42$ in AV10 (Figure 3A, $\mathrm{n}=4, \mathrm{p}<0.01$ ) and increased it in AV20 (Figure 3B, $\mathrm{p}<0.04$ ). In $A \beta 1-42$-expressing $\mathrm{Tau}^{-/-}$mice, A $\beta 1-42$ was significantly higher in AV10 (Figure $3 \mathrm{~A}, \mathrm{n}=4, \mathrm{p}<0.03$ ) and unchanged in AV20 (Figure $3 \mathrm{~B}$ ) or lysosomes (Figure $3 \mathrm{C}$ ) compared to WT. Nilotinib did not alter A $\beta 1-42$ levels in AVs in $\mathrm{Tau}^{-1-}$ mice, suggesting that Tau deletion affects flux through deposition of autophagosomal contents into the lysosomes.
However, Nilotinib decreased A $\beta 1-42$ in AV20 (Figure 3A, $\mathrm{p}<0.05$ ) and increased it in the lysosomes (Figure 3C, $\mathrm{p}<0.001$ ) when lentiviral Tau was co-expressed with $\mathrm{A} \beta 1-42$ in $\mathrm{Tau}^{-/-}$mice, indicating that exogenous Tau restores $A \beta 1-42$ clearance.

Further ELISA measurement of Ser396 p-Tau showed significantly high levels of p-Tau in AV10 (Figure 3D, $\mathrm{n}=4, \mathrm{p}<0.0001$ ) and AV20 (Figure 3E, $\mathrm{p}<0.001$ ) in A 1 1-42 expressing WT mice compared to LacZ (+DMSO), but Nilotinib reduced p-Tau in AV10 (Figure 3D, p < 0.001) and increased it in the lysosomes (Figure 3F, $\mathrm{p}<0.001$ ). Expression of A $\beta 1-42$ together with Tau in WT mice significantly increased $\mathrm{p}$-Tau in AV10 (Figure 3D, $\mathrm{n}=4$, $\mathrm{p}<0.001)$ compared to $A \beta 1-42$ alone, but Nilotinib again reduced $\mathrm{p}$-Tau in AV10 $(\mathrm{p}<0.03)$ and increased it in AV20 (Figure 3E, $\mathrm{p}<0.03$ ). Nilotinib also reduced $\mathrm{p}$-Tau in AV10 (Figure 3D, p $<0.03$ ) and AV20 (Figure 3E, $\mathrm{p}<0.04$ ) in Tau expressing WT mice. Lentiviral Tau expression led to detection of p-Tau in AV10 (Figure 3D) and AV20 (Figure 3E) but not in the lysosomes in $\mathrm{Tau}^{-/-}$ mice and Nilotinib did not alter p-Tau levels, suggesting that exogenous Tau may not affect autophagic p-Tau clearance. However, when Tau was co-expressed with A $\beta 1-42$ in $\mathrm{Tau}^{-/-}$mice, Nilotinib significantly decreased $\mathrm{p}$-Tau in AV10 (Figure 3D, p < 0.01) and AV20 (Figure 3E, $\mathrm{p}<0.05$ ) and increased it in lysosomes (Figure $3 \mathrm{~F}, \mathrm{p}<$ 0.001 ), indicating that exogenous Tau affects $A \beta 1-42$ and p-Tau clearance in $\mathrm{Tau}^{-1-}$ mice.

We previously demonstrated an effect for parkin and Nilotinib on autophagic A $\beta 1-42$ clearance $[14,16]$, so we used lentiviral parkin expression as a control for Nilotinib to show markers of autophagic changes. WB of total brain lysates shows equal V5 levels (Figure $3 \mathrm{G}, \mathrm{n}=5$ ) in WT mice, indicating equal expression of lentiviral clones. Human Tau (HT7) was only detected in WT mice expressing human Tau (Figure 3G) and was decreased in the presence of parkin or Nilotinib $(\mathrm{n}=5, \mathrm{p}<0.05)$, in agreement with ELISA. However, total Tau (Tau-5) and $\mathrm{p}$-Tau (AT8) were increased in Tau $(\mathrm{n}=5, \mathrm{p}<0.05)$ and Tau and $A \beta 1-42(\mathrm{p}<0.05)$ expressing WT mice, but both parkin and Nilotinib decreased p-Tau (38 and $50 \%$, respectively, $\mathrm{p}<0.04$ ) relative to actin. Nilotinib significantly decreased p-Tau at Ser262 (44\%) and Ser 396 (53\%) relative to actin in $\mathrm{A} \beta 1-42$ alone or with Tau in WT mice (Figure $3 \mathrm{H}, \mathrm{n}=5, \mathrm{p}<0.05$ ). 


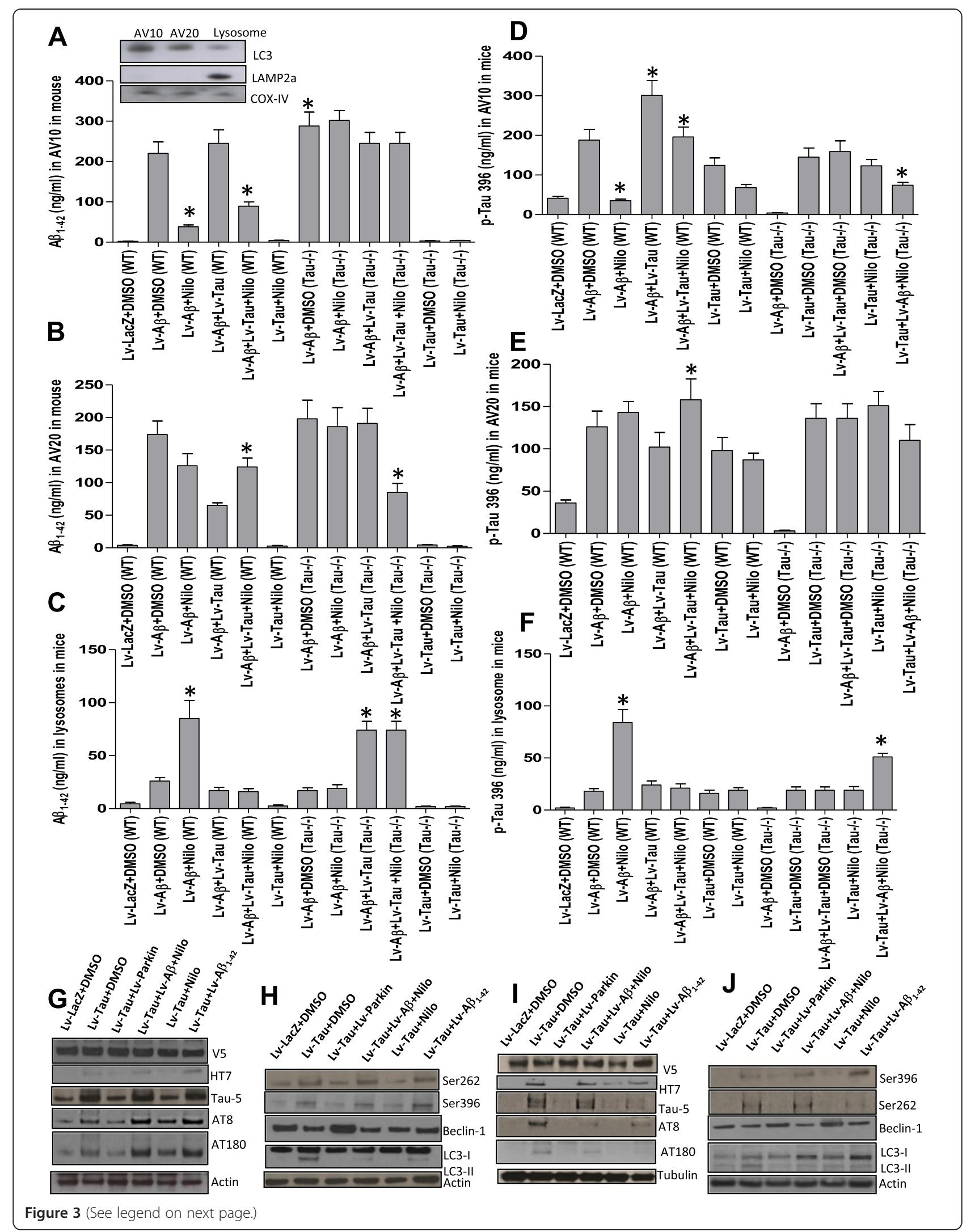


(See figure on previous page.)

Figure 3 Boosting autophagy leads to A $\beta$ 1-42 clearance in WT but not $\mathrm{Tau}^{-/-}$mice. WT and $\mathrm{Tau}^{-/-}$mice were injected with lentiviral Tau $\pm A \beta 1-42$ for 3 weeks and treated I.P. with $10 \mathrm{mg} / \mathrm{kg}$ Nilotinib or DMSO once a day for 3 weeks. Brain tissues were fractionated to isolate AVs and human specific ELISA was performed. Histograms represent concentration of A) AB1-42, insert is WB on 4-12\% SDS NuPAGE gel showing LC3 and LAMP-2a as AV markers, B) AB1-42 in AV20, and C) AB1-42 in lysosomal fractions in WT and Tau ${ }^{-/-}$mice. ELISA concentrations of Ser 396 Tau in D) AV10, E) AV20, and F) lysosomal fractions in WT and Tau ${ }^{-1-}$ mice. WB analysis on 4-12\% SDS NuPAGE gel of total brain extracts from WT mice showing G) V5 to verify equal expression of all lentiviruses, human Tau (HT7), total Tau, AT8 and AT180 relative to actin. H) shows p-Tau Ser 262, Ser 396 and autophagic markers Beclin-1 and LC3-I/II relative to actin. WB analysis on 4-12\% SDS NuPAGE gel of total brain extracts from Tau ${ }^{-1-}$ mice showing I) V5, human Tau (HT7), total Tau, AT8, and AT180 relative to tubulin. J) shows p-Tau Ser 262, Ser 396 and autophagic markers Beclin-1, LC3-I and LC3-II relative to actin. Asterisk indicates significantly different to Aß1-42 + DMSO, bars are mean \pm SEM, two-way ANOVA.

Tau expression decreased the autophagy enzyme, Beclin1 compared to LacZ relative to actin (Figure $3 \mathrm{H}$ and Additional file 1: Figure S1 $1 \mathrm{M}, \mathrm{n}=5$ ), but Nilotinib and parkin increased Beclin-1 levels (40\% and 51\%, respectively, $\mathrm{p}<0.05)$ relative to actin when $\mathrm{A} \beta 1-42$ was expressed alone or together with Tau (Figure $3 \mathrm{H}$ and Additional file 1: Figure S1 $1 \mathrm{M}, \mathrm{n}=5$ ). No significant changes in LC3-I levels (Figure $3 \mathrm{H}$ and Additional file 1: Figure S1 $1 \mathrm{M}, \mathrm{n}=5$ ) were detected in WT mice but LC3II was increased in Tau (100\%) or Tau and A $\beta 1-42$ (44\%) relative to LC3-I or actin (Figure $3 \mathrm{H}$ and Additional file 1: Figure S1 $1 \mathrm{M}, \mathrm{n}=5, \mathrm{p}<0.001)$. LC3-II disappeared in Nilotinib and parkin mice, suggesting enhanced autophagosome clearance. Equal V5 levels (Figure 3I, $\mathrm{n}=5$ ) were also detected in $\mathrm{Tau}^{-/-}$mice, and human Tau (HT7) was only detected in lentiviral Tau expressing $\mathrm{Tau}^{-1-}$ mice (Figure 3I) and disappeared in the presence of parkin or Nilotinib $(n=5)$. Total Tau (Tau-5) and p-Tau (AT8) were detected in Tau expressing mice but both parkin and Nilotinib cleared p-Tau relative to tubulin. Nilotinib eliminated Ser262 and Ser 396 p-Tau when A $\beta 1-42$ was expressed alone or with Tau in $\mathrm{Tau}^{-1-}$ mice (Figure 3J, $\mathrm{n}=5, \mathrm{p}<$ 0.05). Tau expression decreased Beclin-1 compared to LacZ relative to actin $(n=5)$ but Nilotinib and parkin increased Beclin-1 (35\% and 59\%, respectively, $\mathrm{p}<0.05$ ) relative to actin levels when $A \beta 1-42$ was expressed alone or together with Tau (Figure 3J and Additional file 1: Figure S1 $1 \mathrm{M}, \mathrm{n}=5)$. LC3-II significantly increased in Tau (58\%) alone or with A $31-42$ (48\%) relative to LC3-I $(n=5, p<$ 0.05). LC3-II was reversed back to LacZ with Nilotinib and parkin, suggesting autophagosome clearance.

\section{Nilotinib reduces $p$-Tau when exogenous Tau is expressed in $\mathrm{Tau}^{-1-}$ mice}

We determined whether introduction of exogenous Tau affects p-Tau clearance in WT and $\mathrm{Tau}^{-/-}$mice treated with Nilotinib. Labeling with AT8 and 3, 3'-diaminobenzidine (DAB) counterstaining shows endogenous $\mathrm{p}$-Tau in the hippocampus of WT mice injected with a lentivirus driving LacZ expression (Figure $4 \mathrm{~A}, \mathrm{n}=4$, insert shows higher magnification). Human WT Tau increased (Figure $4 \mathrm{U}, 82 \%$, by stereology, insert is higher magnification) $\mathrm{p}$-Tau (Figure $4 \mathrm{~B}, \mathrm{n}=5, \mathrm{p}<0.02$ ) in WT mice treated with DMSO but Nilotinib (Figure 4C, insert is higher magnification) eliminated $\mathrm{p}$-Tau $(\mathrm{n}=5) . \mathrm{A} \beta 1-42$ and Tau together (Figure 4D, insert is higher magnification) increased p-Tau (Figure 4U, 82\%, by stereology, $\mathrm{p}<0.02$ ) compared to LacZ but Nilotinib (Figure 4E) decreased p-Tau (Figure 4U, 35\% higher than control, $\mathrm{p}<0.04)$ in WT mice. No $\mathrm{p}$-Tau was observed in the hippocampus of $\mathrm{Tau}^{-/-}$mice (Figure 4F, insert is high magnification) but human Tau expression (Figure 4G, insert is higher magnification) led to $\mathrm{p}$-Tau in $\mathrm{Tau}^{-/-}$ mice with DMSO, while Nilotinib reduced (Figure $4 \mathrm{U}, 41 \%$, $\mathrm{n}=5, \mathrm{p}<0.05$ ) $\mathrm{p}$-Tau (Figure $4 \mathrm{H}$, insert is higher magnification). Co-expression of $\mathrm{A} \beta 1-42$ and Tau (Figure 4J, insert is higher magnification) increased $\mathrm{p}$-Tau that was not different than Tau alone (Figure 4I) but Nilotinib reduced (19\%) p-Tau (Figure 4J, $\mathrm{n}=5$, insert is higher magnification) compared to DMSO. Injection of lentiviral Tau into the hippocampus also increased p-Tau (AT180) (91\%, by stereology) in the cortex in mice (Figure $4 \mathrm{~L}$, $\mathrm{n}=5, \mathrm{p}<0.03)$ treated with DMSO compared to LacZ (Figure $4 \mathrm{~K}$ ), but Nilotinib (Figure $4 \mathrm{M}, \mathrm{n}=5$ ) reduced $\mathrm{p}$-Tau $(45 \%, \mathrm{p}<0.05)$. A $\beta 1-42$ and Tau together (Figure $4 \mathrm{~N}$, $\mathrm{n}=5)$ increased $\mathrm{p}$-Tau levels $(69 \%$, by stereology, $\mathrm{p}<0.04$ ) compared to LacZ but Nilotinib (Figure 4O) decreased p-Tau ( $62 \%$ by stereology, $\mathrm{p}<0.04)$ in WT mice. No p-Tau was observed in the cortex of $\mathrm{Tau}^{-/-}$mice (Figure 4P) but human Tau expression (Figure 4Q) increased p-Tau in $\mathrm{Tau}^{-/-}$mice with DMSO, while Nilotinib reduced (56\%, $\mathrm{n}=5, \mathrm{p}<0.05) \mathrm{p}$-Tau (Figure $4 \mathrm{R}$ ) compared to DMSO (Figure 4Q). Co-expression of A 1-42 and Tau increased pTau (Figure 4S, 29\%) compared to Tau alone and Nilotinib significantly reduced $\mathrm{p}$-Tau levels (Figure $4 \mathrm{~T}, \mathrm{n}=5,31 \%$, $\mathrm{p}<0.05$ ) compared to DMSO (Figure $4 \mathrm{U}$ ) in $\mathrm{Tau}^{-/-}$mice.

\section{Tau deletion reduces intracellular $A \beta 1-42$ and contributes to plaque formation}

We determined whether Tau deletion affects the distribution of intracellular and extracellular A $\beta 1-42$. Plaque deposition was observed in the hippocampus of WT mice expressing $\mathrm{A} \beta 1-42$ at 1 month post-injection (Figure 5A, $\mathrm{n}=5$ ). Nilotinib significantly decreased (by stereology) intracellular $\mathrm{A} \beta 1-42$ (Figure $5 \mathrm{~B}$ and $\mathrm{U}, \mathrm{n}=5, \mathrm{p}<0.01$ ), which was also verified with human specific $A \beta 1-42$ antibody staining as shown in Additional file 1: Figure S1. Nilotinib reduced plaque load (Figure $5 \mathrm{~B}$ and $\mathrm{V}, \mathrm{p}<0.001$ ) 


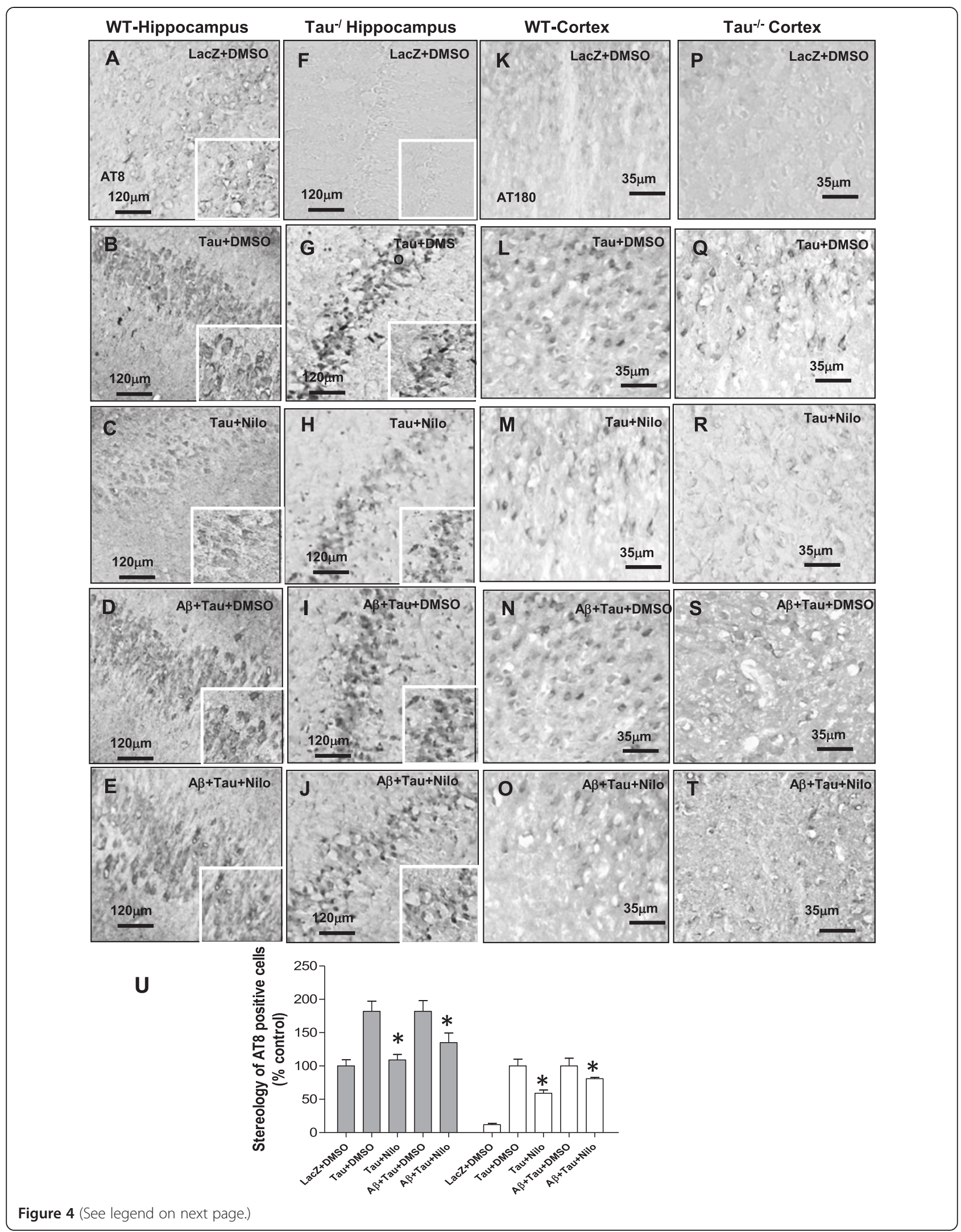


(See figure on previous page.)

Figure $4 \mathrm{~A} \beta 1-42$ is more efficiently cleared in WT than $\mathrm{Tau}^{-/-}$mice. Staining of $20 \mu \mathrm{m}$ thick coronal sections with p-Tau (AT8) and counterstained with DAB in A) LacZ + DMSO, B) Tau + DMSO, C) Tau + Nilotinib, D) Tau and A 1 1-42 + DMSO and E) Tau and A $1-42+$ Nilotinib. Staining of hippocampus

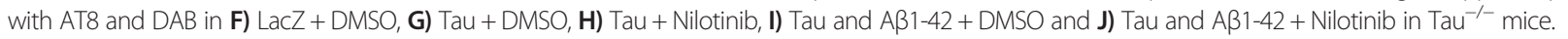
Staining of $20 \mu \mathrm{m}$ thick coronal sections with p-Tau (AT180) and DAB in K) LacZ + DMSO, L) Tau + DMSO, M) Tau + Nilotinib, N) Tau and Aß1-42 + DMSO and $\mathbf{O})$ Tau and A 1 1-42 + Nilotinib in WT mice. Staining of cortical sections in P) LacZ + DMSO, Q) Tau + DMSO, R) Tau + Nilotinib, S) Tau and A 1 -42 + DMSO and T) Tau and AB1-42 + Nilotinib in Tau ${ }^{-/-}$mice. U) Histograms represent stereological quantification of p-Tau. Asterisk indicates significantly different to $A \beta 1-42+D M S O$, bars are mean \pm SEM, two-way ANOVA.

compared to DMSO (Figure $5 \mathrm{~A}, \mathrm{n}=5$ ) in WT mice expressing $A \beta 1-42$ alone, consistent with our previously published data $[14,23]$. Tau and A $\beta 1-42$ increased plaque levels (Figure $5 \mathrm{C}$ and $\mathrm{V}, \mathrm{n}=5, \mathrm{p}<0.02$ ) in WT mice treated with DMSO and Nilotinib significantly decreased intracellular $\mathrm{A} \beta 1-42$ (Figure 5D and $\mathrm{U}, \mathrm{p}<0.02$ ) and plaque load (Figure 5D and V, $\mathrm{p}<0.001$ ) compared to $\mathrm{A} \beta 1-42$ alone or LacZ (Figure 5E and U, $\mathrm{p}<0.001, \mathrm{n}=5$ ). Nilotinib did not alter intracellular $A \beta 1-42$ staining (Figure $5 \mathrm{G}$ and $\mathrm{U}, \mathrm{n}=5$ ) or plaque load (Figure $5 \mathrm{G}$ and $\mathrm{V}$ ) in the hippocampus of $\mathrm{Tau}^{-/-}$mice compared to DMSO (Figure 5F, $\mathrm{n}=5$ ), which displayed more plaque (Figure $5 \mathrm{~F}$ and V, $\mathrm{p}<0.001, \mathrm{n}=5$ ) and less intracellular $A \beta 1-42$ (Figure $5 \mathrm{~F}$ and $\mathrm{U}, \mathrm{p}<0.001$ ) $\mathrm{A} \beta$ compared to WT mice (Figure 5A). Tau expression with $\mathrm{A} \beta 1-42$ in $\mathrm{Tau}^{-1-}$ mice increased intracellular $\mathrm{A} \beta 1$ 42 (Figure $5 \mathrm{H}$ and $\mathrm{U}, \mathrm{p}<0.01, \mathrm{n}=5$ ) and decreased plaque levels (Figure $5 \mathrm{H}$ and $\mathrm{V}, \mathrm{p}<0.05$ ) while Nilotinib reversed intracellular A $\beta 1-42$ (Figure 5I and U, p $<0.001$ ) and plaque (Figure $5 \mathrm{I}$ and $\mathrm{V}, \mathrm{p}<0.001$ ) back to WT levels (Figure 5D). No A $31-42$ staining was observed in mice expressing LacZ (Figure 5J). Plaque deposition and intracellular A $\beta 1-42$ were also detected in the cortex of WT mice expressing $A \beta 1-42$ alone (Figure $5 \mathrm{~K}$ ) or together with Tau (Figure $5 \mathrm{M}$ ) while Nilotinib reduced $\mathrm{A} \beta 1-42$ staining (Figure 5L and N) compared to DMSO (Figure 5K and $\mathrm{I}$ ) and LacZ (Figure 5O, $\mathrm{n}=5$ ). Plaque deposition was higher in the cortex of $\mathrm{Tau}^{-/-}$mice expressing $\mathrm{A} \beta 1$ 42 alone (Figure 5P) or together with Tau (Figure 5R) while Nilotinib reduced A $\beta 1-42$ staining only when Tau was introduced (Figure $5 \mathrm{~S}$ ) compared to $\mathrm{A} \beta 1-42$ alone (Figure 5Q and I) and LacZ (Figure 5T, n =5).

\section{Tau deletion attenuates $A \beta 1-42$-induced cell death despite the increase in plaque load}

To determine whether Tau deletion affects cell viability in parallel with the distribution of intracellular and plaque $A \beta 1-42$, cell death was assessed via silver staining that detects degenerating fibers and neurons and caspase- 3 activity. A $\beta 1-42$ expression (+DMSO) increased the number of silver-positive cells (Figure 6A and $\mathrm{K}, \mathrm{n}=5, \mathrm{p}<0.05$ ) compared to LacZ (Figure 6E and $\mathrm{K}$ ) in WT mice and Nilotinib eliminated cell death (Figure 6B). An increase in silver-stained cells was detected when Tau was expressed together with $\mathrm{A} \beta 1-42$ (Figure $6 \mathrm{C}$ and $\mathrm{K}, \mathrm{n}=5, \mathrm{p}<0.05$ ) and again Nilotinib reduced cell death (Figure $6 \mathrm{D}$ and $\mathrm{K}$ ) in WT mice. In $\mathrm{Tau}^{-1-}$ mice, A $\beta 1-42$ (+DMSO) also increased the number of silver-positive cells (Figure $6 \mathrm{~F}$ and $\mathrm{K}, \mathrm{n}=5, \mathrm{p}<0.05$ ) compared to LacZ (Figure 6J and $\mathrm{K}$ ) but this increase remained significantly lower than WT (Figure 6A and $\mathrm{K}, \mathrm{p}<0.05$ ), suggesting that Tau deletion attenuates $A \beta 1-42$ toxicity. In contrast with WT mice, Nilotinib did not reduce A $31-42$-induced cell death in $\mathrm{Tau}^{-1-}$ mice (Figure 6G). Exogenous Tau and A $\beta 1-42$ together increased cell death (Figure $6 \mathrm{H}$ and $K, n=5$, $\mathrm{p}<0.01$ ), which remained lower than WT (Figure 6A) but Nilotinib completely reversed cell death (Figure 6I and $\mathrm{K})$, indicating that Tau is needed to mediate autophagic clearance and reduce A $\beta 1-42$ toxicity. Caspase-3 activity was also increased in WT mice expressing A $\beta 1-42$ alone or together with Tau (Figure 6L, n = 5, p < 0.025) but Nilotinib reversed these effects. Although A $\beta 1-42$ increased caspase- 3 activity with and without Tau (Figure 6L, $\mathrm{n}=5, \mathrm{p}<0.05$ ), Nilotinib reversed these effects only when Tau was co-expressed with A $\beta 1-42$.

\section{Discussion}

These studies demonstrate that autophagic intracellular A $1-42$ clearance requires Tau, suggesting that normal Tau function modulates plaque deposition via regulation of intracellular A $31-42$ degradation. Inhibition of either the proteasome or autophagy led to partial $A \beta 1-42$ and p-Tau clearance, suggesting that $A \beta 1-42$ and $p$-Tau may be degraded via either autophagy and/or the proteasome. Tau deletion impaired intracellular $\mathrm{A} \beta$ clearance and increased extracellular plaque formation, while introduction of human Tau into $\mathrm{Tau}^{-/-}$brains restored autophagic A $31-42$ and p-Tau clearance and reduced plaques. We previously demonstrated that the E3 ubiquitin ligase parkin is essential for Nilotinib-induced autophagic amyloid clearance [14]. However, parkin and Tau differentially alter autophagic flux. Parkin deletion affects the transfer of A 1 1-42 and p-Tau from pre-lysosomal AVs, suggesting impairment of the earlier steps of the sequestration process $[14,16]$. Tau deletion affects the deposition of amyloids from AVs into the lysosomes, indicating that Tau is required for the completion of autophagic clearance. However, impairment of autophagic flux with either Tau or parkin deletion leads to plaque deposition, further suggesting that reduction of intracellular A $\beta 1-42$ clearance may lead to its secretion. Nilsson et al. [24] recently 


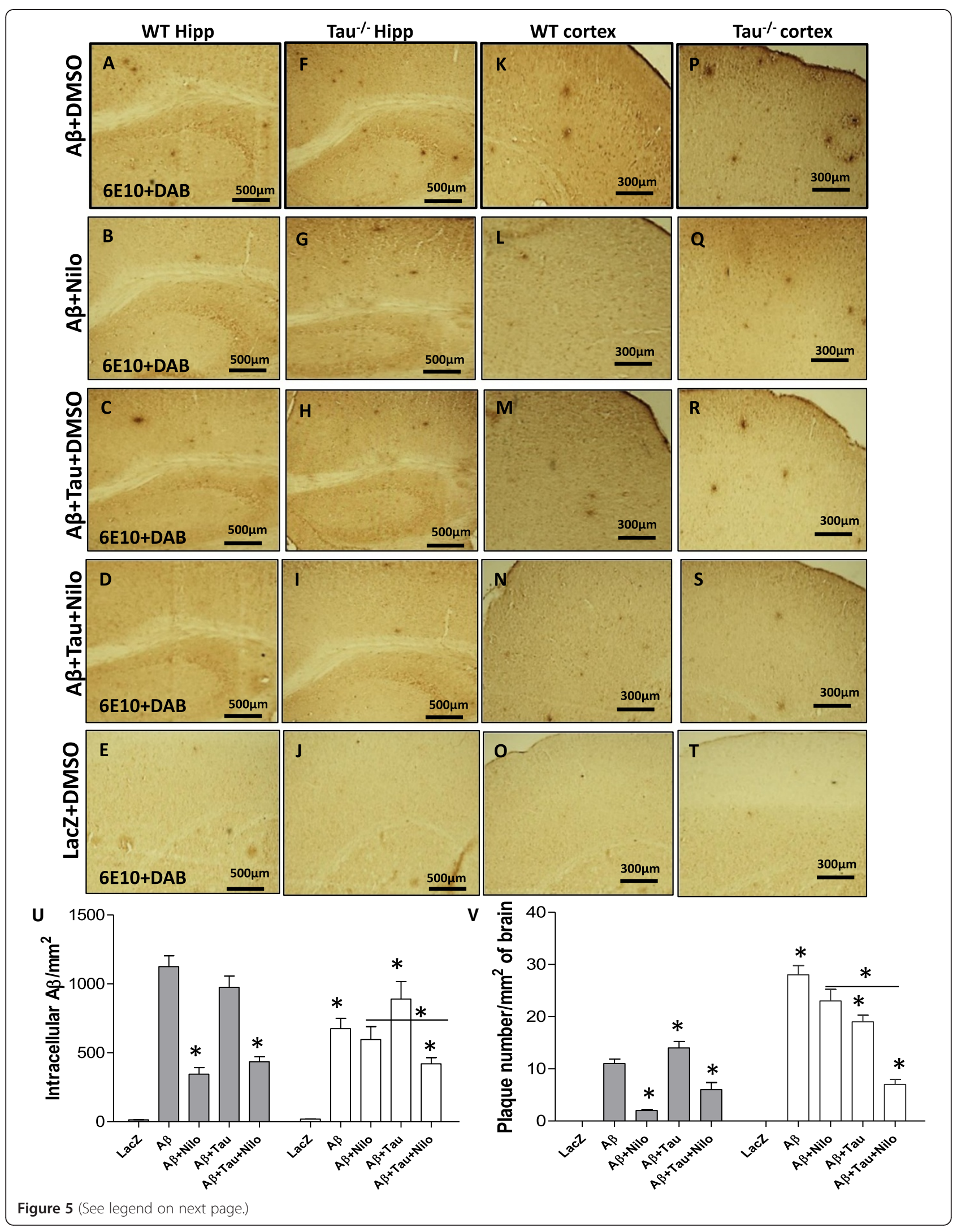




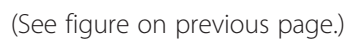

showed that blocking autophagy via ATG7 deletion in $\mathrm{AD}$ mouse diminishes extracellular $\mathrm{A} \beta$ release, increases its intracellular level and reduces extracellular amyloid plaque. Our results suggest that Tau deletion reduces intracellular $A \beta$ level and increases plaque build-up. Nilsson et al. [24] model inhibited autophagy at an early pre-autophagosomal level where an ubiquitin-like reaction involving ATGs triggers autophagy, leading to autophagosome formation and subsequent maturation [22]. Our model demonstrated impairment of autophagic flux at a later pre-lysosomal stage, where $A \beta$ and/or Tau have already accumulated in autophagosomes without deposition into the lysosomes. Thus, $A \beta$ release and plaque formation may depend on the type of impairment along the autophagic cascade, suggesting that preautophagosomal inhibition of flux results in intracellular accumulation and less $A \beta$ secretion whereas arrest of autophagic flux after $A \beta$ deposition in undigested autophagosomes leads to $A \beta$ secretion and plaque formation.

Tau maybe required to facilitate autophagosome maturation and retrograde transport from distal axons towards cell bodies to fuse with lysosomes [25], thus contributing to modulation of autophagic flux. Our data suggest that Tau deletion reduces intracellular $A \beta$ degradation [14], which may be due in part to axonal changes that affect efficient autophagosome fusion with the lysosome in the $\mathrm{Tau}^{-/-}$mouse, which is reported to have impaired organelle movement $[20,21]$. The normal role of Tau in autophagy was shown in cellular models of Niemann-Pick type $\mathrm{C}$ (NPC) disease showing that acute reductions of Tau in NPC1-deficient fibroblasts impairs autophagy [26]. As autophagy is up-regulated in NPC and protein degradation may depend on movement along microtubules, Tau knockdown aggravates NPC pathology through a mechanism independent of Tau aggregation [27] as is often observed in neurodegenerative diseases, further suggesting a critical role for normal Tau in the regulation of autophagy. Taken together these data raise the possibility that loss of Tau function via mutations, deletion or hyper-phosphorylation may lead to decreased Tau binding to microtubules and subsequent impairment of autophagic flux, which may alter the distribution of intracellular and extracellular A $\beta 1-42$ overtime. Tau may affect autophagic flux via interaction with autophagy enzymes, including Beclin-1 and the microtubule associated protein A/B light chain (MAPA/BLC)-3. We previously showed that p-Tau co-localizes with LC3 in rat brains expressing WT or mutant P301L Tau [28] and the elucidation of the molecular mechanisms underlying interaction between Tau and autophagy proteins is an area for future investigation.

A number of studies suggested that facilitation of Tau clearance via up-regulation of the proteasome or autophagy can protect cells from age-related stress [29,30]. Previous studies showed that impaired autophagy may affect proteasomal activity [31], but the interplay between autophagy and the proteasome may not be a simple compensatory relationship. Our studies show that loss of normal Tau function via deletion impairs autophagic flux, independent of proteasomal activity. We demonstrated that introduction of WT Tau into $\mathrm{Tau}^{-1-}$ mice partially restores autophagic A $\beta 1-42$ clearance, indicating that exogenous human Tau expression may affect A $\beta 1-42$ levels. Expression of exogenous Tau may restore $A \beta 1-42$ clearance due to possible integration of Tau into microtubules, leading to facilitation of autophagy. However, the relationship between $A \beta$ and Tau is contentious with more recent in vivo reports demonstrating that Tau deletion prevents $A \beta$ toxicity, and previous cell culture studies showing that $A \beta$ triggers Tau pathology (reviewed in [32]). Our data show that Tau deletion exacerbates extracellular plaque build-up but attenuates cell death, indicating that Tau may modulate $A \beta 1-42$ toxicity via alteration of intracellular and extracellular A $\beta 1-42$ levels. Clinically, some aged human brains have plaques with no associated dementia or major cognitive decline $[10,11]$. However, $A \beta$ and Tau together are often associated with dementia [12] and Tau mutations and/or accumulation are causal to some neurodegenerative diseases that do not display $\beta$-amyloid pathology, including FTDP-17, PSP, and CBD, suggesting that Tau associated neurodegeneration can occur independently of plaque deposition [6,7]. Taken together, these clinical findings support our hypothesis that Tau may be a critical modulator of A $\beta 1-42$ toxicity through autophagic clearance of toxic intracellular A $\beta 1-42$ [13], which may be secreted when autophagy fails, leading to extracellular plaque deposits.

In conclusion, loss of normal Tau function may alter microtubule stability and affect the execution of autophagy. 


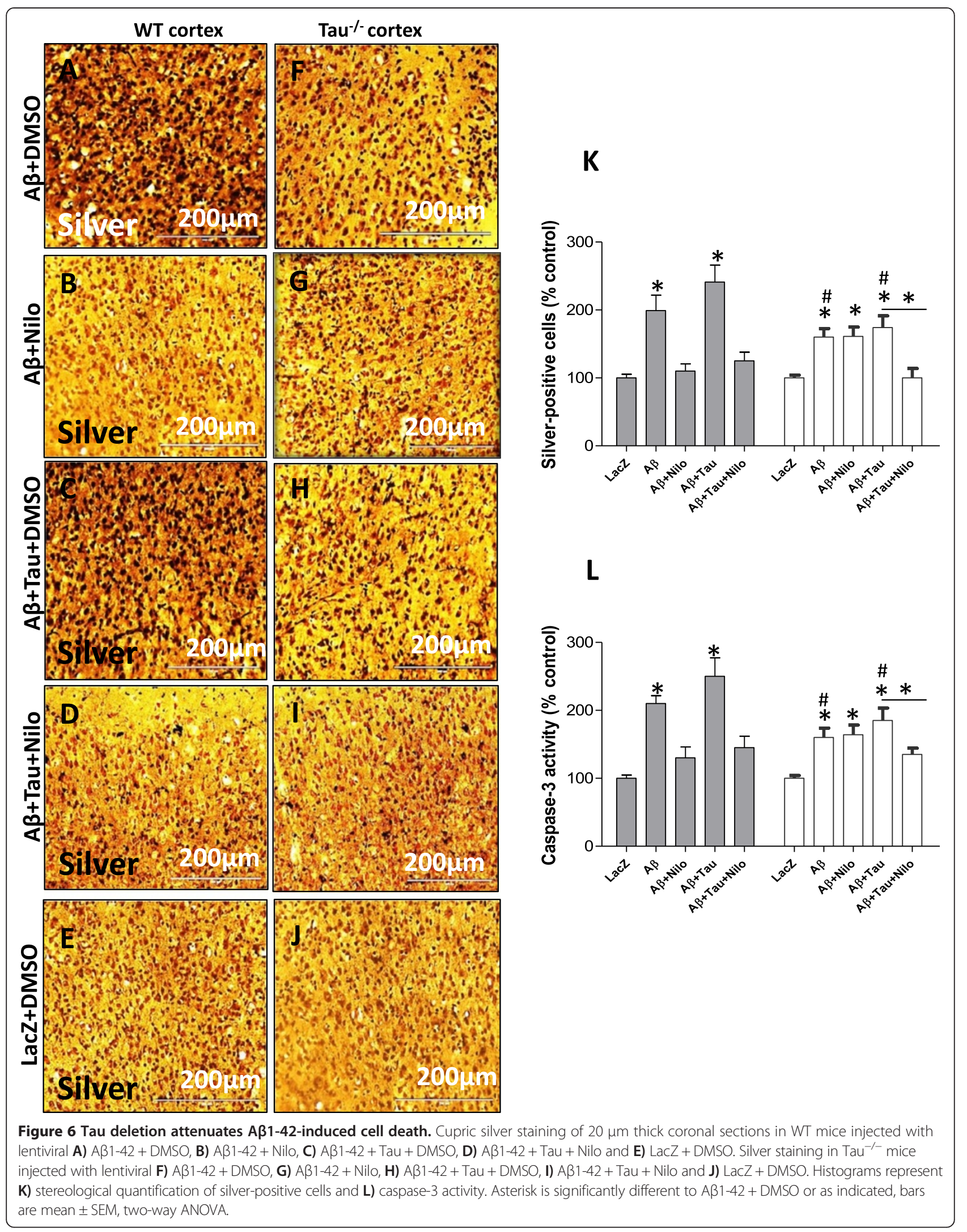


Our findings agree with previous studies that basal autophagy is essential and elevated autophagic activity is beneficial for neurons to prevent accumulation of protein aggregates [33-36]. The current studies demosntrate that Tau is required to mediate the beneficial effects of autophagic clearance. Boosting autophagy was shown to reduce free unbound p-Tau and spare microtubule associated protein Tau in models of neurodegeneration [14,37]. The current studies suggest that Tau function regulates intracellular A $31-42$ clearance and affects extracellular plaque deposition.

\section{Methods}

\section{Primary hippocampal neuronal culture}

Fetal WT hippocampal tissue (gestation E15) were dissected and gently triturated with a fire-polished Pasteur pipette, and the resulting pool of dissociated cells were plated in 35-mm dishes precoated with polyethyleneimine (1 mg/ml) (MP Biomedicals NC-N19544450) containing $0.5 \mathrm{ml}$ basal growth medium, which was supplemented with $5 \%$ horse serum and $0.5 \%$ fetal calf serum and replaced with fresh medium every three days. DIV 14 or when the density of cells reached $3 \times 10^{4}$ cells, neurons were infected with $3 \mu \mathrm{l}$ lentiviruses for $24 \mathrm{hrs}$ and then treated with $10 \mu \mathrm{M}$ Nilotinib (AMN-107, NC0604306, SELLECK CHEMICAL LLC) or $1 \mu \mathrm{L}$ DMSO for $24 \mathrm{hrs}$ or 100 nM Bafilomycin-A1(AC32812-0001, Acros Organics) or $20 \mu \mathrm{M}$ MG132 (NC9819784, Cayman Chemicals) for $6 \mathrm{hrs}$.

\section{Stereotaxic injection}

Lentiviral constructs driving LacZ, human WT Tau and/ or A $\beta 1-42$ were stereotaxically injected at $1 \times 10^{6}$ multiplicity of infection (MOI) into the right CA1 hippocampus of 1 year old male C57BL/6 or $\mathrm{Tau}^{-/-}$as we previously explained [14,18]. All procedures were approved by the Georgetown University Animal Care and Use Committee (GUACUC). Nilotinib was dissolved in DMSO and a total volume of $30 \mu \mathrm{l}$ was I.P. injected once a day for 3 weeks. Half the animals received DMSO and the other half received Nilotinib in DMSO.

\section{WB analysis}

To extract the soluble protein fraction, brain tissue or cells were isolated and homogenized in $1 \times$ STEN buffer (50 mM Tris (pH 7.6), $150 \mathrm{mM} \mathrm{NaCl}, 2 \mathrm{mM}$ EDTA, $0.2 \%$ NP-40, 0.2\% BSA, $20 \mathrm{mM} \mathrm{PMSF}$ and protease cocktail inhibitor), centrifuged at 10,000 g for $20 \mathrm{~min}$ at $4^{\circ} \mathrm{C}$ and the supernatant containing the soluble protein fraction was collected. To extract insoluble $A \beta 1-42$, the pellet was re-suspended in 30\% formic acid and centrifuged at $10,000 \mathrm{~g}$ for $20 \mathrm{~min}$ at $4{ }^{\circ} \mathrm{C}$ and the supernatant was collected. Extracts were analyzed by WB on SDS NuPAGE 4-12\% Bis-Tris gel (Invitrogen, NP0301BOX). $\beta$-actin was probed $(1: 1000)$ with polyclonal antibody (ThermoScientific, PA121167). Autophagy antibodies, including Beclin-1 (1:1000) and LC3-B (1:1000) were used to probe according to autophagy antibody sampler kit (Cell Signaling, Inc. Cat\# 4445). Tau antibodies were used as we previously described $[14,18]$. WBs were quantified by densitometry using Quantity One 4.6.3 software (Bio Rad).

\section{IHC of brain sections}

Animals were deeply anesthetized with a mixture of (1:8) Xylazine (Edgewood Pharmacy, 20130822) and Ketamine (Butler Animal Health Supply, 023061), washed with 1× saline for $1 \mathrm{~min}$ and then perfused with 4\% (PFA) paraformaldehyde (MP Biomedicals, ICN15014601) for 1520 min. Brains were quickly dissected out and immediately stored in $4 \%$ PFA for 24 hrs at $4^{\circ} \mathrm{C}$ and then transferred to $30 \%$ sucrose at $4^{\circ} \mathrm{C}$ for $48 \mathrm{~h}$. Tissues were cut using a cryostat at $4^{\circ} \mathrm{C}$ into $20 \mu \mathrm{m}$ thick sections and stored at $-20^{\circ} \mathrm{C}$. Cupric silver and immuno-staining were performed as we previously described $[14,18]$.

Stereological methods were applied by a blinded investigator using unbiased stereology analysis (Stereologer, Systems Planning and Analysis, Chester, MD) to determine the total positive cell counts in 20 cortical/hippocampal fields on at least 10 brain sections $(\sim 400$ positive cells per animal) from each animal.

Quantification of plaque load or counting plaque number was performed by a blind investigator using ImageJ by drawing a line around individual plaques within $1 \mathrm{~mm}^{2}$ radius of 6 randomly selected hippocampal and cortical regions in $6 \mathrm{E} 10$ stained slides. The number of plaques was averaged per $\mathrm{mm}^{2}$ and compared between treatment condition, as we previously described $[14,18]$.

\section{Subcellular fractionation for isolation of autophagic compartments}

A total of $0.5 \mathrm{~g}$ of animal brains were homogenized at low speed (Cole-Palmer homogenizer, LabGen 7, 115 Vac) in $1 \times$ STEN buffer and centrifuged at $1,000 \mathrm{~g}$ for $10 \mathrm{~min}$ to isolate the supernatant from the pellet. The pellet was re-suspended in 1× STEN buffer and centrifuged once to increase the recovery of lysosomes. The pooled supernatants were then centrifuged at 100,000 rpm for $1 \mathrm{hr}$ at $4^{\circ} \mathrm{C}$ to extract the pellet containing autophagic vacuoles (AVs) and lysosomes. The pellet was re-suspended in $10 \mathrm{ml}(0.33 \mathrm{~g} / \mathrm{ml}) 50 \%$ Metrizamide (Acros Organics, AC22943-0250) and $10 \mathrm{ml}$ in cellulose nitrate tubes. A discontinuous Metrizamide gradient was constructed in layers from bottom to top as follows: $6 \mathrm{ml}$ of pellet suspension, $10 \mathrm{ml}$ of $26 \%$; $5 \mathrm{ml}$ of $24 \%$; $5 \mathrm{ml}$ of $20 \%$; and $5 \mathrm{ml}$ of $10 \%$ Metrizamide [38]. After centrifugation at $10,000 \mathrm{rpm}$ for $1 \mathrm{hr}$ at $4^{\circ} \mathrm{C}$, the fraction floating on the 10\% layer (Lysosome) and the fractions banding at the 
24\%/20\% (AV 20) and the 20\%/10\% (AV10) Metrizamide inter-phases were collected by a syringe and examined.

\section{$20 \mathrm{~S}$ proteasome activity assay}

Human M17 neuroblastoma cells were co-transfected with $3 \mu \mathrm{g}$ Tau, LacZ or Aß1-42 cDNAs for $24 \mathrm{hrs}$ and then treated with $10 \mu \mathrm{M}$ Nilotinib for additional $24 \mathrm{hrs}$ (48 hrs total). Either $20 \mu \mathrm{M}$ proteasomal inhibitor MG132 or $100 \mathrm{nM}$ autophagy inhibitor Bafilomycin-A1 were applied for $6 \mathrm{hrs}$ prior to the beginning of proteasome activity assays. Cell extracts $(100 \mu \mathrm{g})$ were incubated with $250 \mu \mathrm{M}$ of the fluorescent $20 \mathrm{~S}$ proteasome specific substrate Succinyl-LLVY-AMC (Enzo Life Sciences, BML-P802-0005) at $37^{\circ} \mathrm{C}$ for $2 \mathrm{hrs}$. The medium was discarded and proteasome activity was measured in tissue homogenates

$A \beta$ and $p$-Tau enzyme-linked immunosorbent assay (ELISA) Specific p-Tau ser396 (Invitrogen, KHB7031) and A $\beta_{1-42}$ (Invitrogen, KHB3442,) ELISA were performed according to manufacturer's protocol as described $[15,19]$. Caspase-3 activity assays were performed according to manufacturer's protocol as we previously described $[14,18]$.

\section{Statistical analysis}

Data were analyzed with GraphPad software (GraphPad Prism, CA) using two-way ANOVA. The number of experiments and $p$ values are indicated in the text.

qRT-PCR in primary hippocampal neuronal culture was performed on Real-time OCR system with Fast SYBRGreen PCR master Mix (Applied Biosystems, NC0381818) in triplicate from reverse-transcribed cDNA from mouse primary cortical neurons injected with lentiviral LacZ, Tau and/or A $\beta 1-42$ (24 hrs) treated with DMSO or Nilotinib (24 hrs) using the same primers that were utilized to clone human A $\beta 1-42$ [13] or Tau [19] into the lentivirus. Gene expression values were normalized using GADPH levels.

\section{Additional file}

Additional file 1: Figure S1. To verify equal expression of lentiviral clones, $20 \mu \mathrm{m}$ thick coronal brain sections were stained human specific A) AB1-42 and B) V5 and C) merged figure showing that both LacZ and $A \beta 1-42$ were co-expressed. Endogenous phosphorylated Tau using D) AT8 and E) V5 and I) merged figure showing LacZ expression. Lentiviral

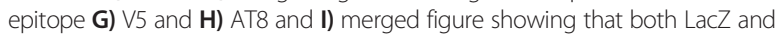
Tau were co-expressed. Human specific J) AB1-42, K) AT8 and L) merged figure shows that Tau and of A $1-42$ were co-expressed. Histograms represent $\mathbf{M}$ ) densitometry of Beclin-1 relative to actin and LC3-II relative to LC3-I in WT and $\mathrm{Tau}^{-/-}$mice. Asterisk is significantly different to A $1-42+$ DMSO, bars are mean \pm SEM, two-way ANOVA.

\section{Competing interests}

Georgetown University and one or more authors have intellectual property interests in technology related to this research.

\section{Authors' contributions}

$\mathrm{L}, \mathrm{MH}$ and WC performed the WB, $\mathrm{HC}$ and other biochemical and analytical assays. IL packaged the lentiviruses and CM injected the animals, analyzed the data and wrote the manuscript. JS provided scientific input, revised and edited the manuscript. All authors read and approved the final manuscript.

\section{Acknowledgments}

Funding for these studies was provided by Merck \& Co and Georgetown University grants to Charbel Moussa.

\section{Author details}

'Department of Neuroscience, Laboratory for Dementia and Parkinsonism, Georgetown University Medical Center, 3970 Reservoir RD, Washington, DC 20057, USA. ²Department of Traditional Chinese Medicine, Xuanwu Hospital, Capital Medical University, Beijing 100053, China. ${ }^{3}$ Neuroscience Discovery, Merck Research Laboratories, 770 Sunneytown Pike, West Point, PA 19486, USA.

Received: 20 August 2014 Accepted: 21 October 2014

Published: 10 November 2014

\section{References}

1. Selkoe DJ: Alzheimer's disease: genes, proteins, and therapy. Physio/ Rev 2001, 81:741-766.

2. Gotz J, Chen F, van Dorpe J, Nitsch RM: Formation of neurofibrillary tangles in P301I tau transgenic mice induced by Abeta 42 fibrils. Science 2001, 293:1491-1495.

3. King ME, Kan HM, Baas PW, Erisir A, Glabe CG, Bloom GS: Tau-dependent microtubule disassembly initiated by prefibrillar beta-amyloid. J Cell Biol 2006, 175:541-546.

4. Roberson ED, Scearce-Levie K, Palop JJ, Yan F, Cheng IH, Wu T, Gerstein H, Yu GQ, Mucke L: Reducing endogenous tau ameliorates amyloid beta-induced deficits in an Alzheimer's disease mouse model. Science 2007, 316:750-754

5. Vossel KA, Zhang K, Brodbeck J, Daub AC, Sharma P, Finkbeiner S, Cui B, Mucke $L$ : Tau reduction prevents Abeta-induced defects in axonal transport. Science 2010, 330:198.

6. See TM, LaMarre AK, Lee SE, Miller BL: Genetic causes of frontotemporal degeneration. J Geriatr Psychiatry Neurol 2010, 23:260-268.

7. Short RA, Graff-Radford NR, Adamson J, Baker M, Hutton M: Differences in tau and apolipoprotein E polymorphism frequencies in sporadic frontotemporal lobar degeneration syndromes. Arch Neurol 2002, 59:611-615

8. Giannakopoulos P, Herrmann FR, Bussiere T, Bouras C, Kovari E, Perl DP, Morrison JH, Gold G, Hof PR: Tangle and neuron numbers, but not amyloid load, predict cognitive status in Alzheimer's disease. Neurology 2003, 60:1495-1500.

9. Ethell DW: An amyloid-notch hypothesis for Alzheimer's disease Neuroscientist 2010, 16:614-617

10. Balasubramanian $\mathrm{AB}$, Kawas $\mathrm{CH}$, Peltz CB, Brookmeyer R, Corrada MM: Alzheimer disease pathology and longitudinal cognitive performance in the oldest-old with no dementia. Neurology 2012, 79:915-921.

11. Kawas CH, Greenia DE, Bullain SS, Clark CM, Pontecorvo MJ, Joshi AD, Corrada MM: Amyloid imaging and cognitive decline in nondemented oldest-old: the 90+ Study. Alzheimers Dement 2013, 9:199-203.

12. Robinson JL, Geser F, Corrada MM, Berlau DJ, Arnold SE, Lee VM, Kawas CH, Trojanowski JQ: Neocortical and hippocampal amyloid-beta and tau measures associate with dementia in the oldest-old. Brain 2011, 134:3708-3715.

13. Rebeck GW, Hoe HS, Moussa CE: Beta-amyloid1-42 gene transfer model exhibits intraneuronal amyloid, gliosis, tau phosphorylation, and neuronal loss. J Biol Chem 2010, 285:7440-7446.

14. Lonskaya I, Hebron ML, Desforges NM, Franjie A, Moussa CE: Tyrosine kinase inhibition increases functional parkin-Beclin-1 interaction and enhances amyloid clearance and cognitive performance. EMBO Mol Med 2013, 5:1247-1262

15. Burns MP, Zhang L, Rebeck GW, Querfurth HW, Moussa CE: Parkin promotes intracellular Abeta1-42 clearance. Hum Mol Genet 2009, 18:3206-3216.

16. Lonskaya I, Hebron ML, Desforges NM, Schachter JB, Moussa CE: Nilotinib-induced autophagic changes increase endogenous parkin level and ubiquitination, leading to amyloid clearance. J Mol Med (Berl) 2014, 92(4):373-386 
17. Lonskaya I, Shekoyan AR, Hebron ML, Desforges N, Algarzae NK, Moussa CE: Diminished parkin solubility and co-localization with intraneuronal amyloid-beta are associated with autophagic defects in Alzheimer's disease. J Alzheimers Dis 2013, 33:231-247.

18. Khandelwal PJ, Herman AM, Hoe HS, Rebeck GW, Moussa CE: Parkin mediates beclin-dependent autophagic clearance of defective mitochondria and ubiquitinated Abeta in AD models. Hum Mol Genet 2011, 20:2091-2102.

19. Khandelwal PJ, Dumanis SB, Herman AM, Rebeck GW, Moussa CE: Wild type and P301L mutant Tau promote neuro-inflammation and alphaSynuclein accumulation in lentiviral gene delivery models. Mol Cell Neurosci 2012, 49:44-53.

20. Dawson HN, Cantillana V, Jansen M, Wang H, Vitek MP, Wilcock DM, Lynch $J R$, Laskowitz DT: Loss of tau elicits axonal degeneration in a mouse model of Alzheimer's disease. Neuroscience 2010, 169:516-531.

21. Jimenez-Mateos EM, Gonzalez-Billault C, Dawson HN, Vitek MP, Avila J: Role of MAP1B in axonal retrograde transport of mitochondria. Biochem J 2006, 397:53-59.

22. Klionsky DJ, Abdalla FC, Abeliovich H, Abraham RT, Acevedo-Arozena A, Adeli K, Agholme L, Agnello M, Agostinis P, Aguirre-Ghiso JA, Ahn HJ, Ait-Mohamed O, Ait-Si-Ali S, Akematsu T, Akira S, Al-Younes HM, Al-Zeer MA, Albert ML, Albin RL, Alegre-Abarrategui J, Aleo MF, Alirezaei M, Almasan A, Almonte-Becerril M, Amano A, Amaravadi R, Amarnath S, Amer AO, Andrieu-Abadie N, Anantharam V, et al: Guidelines for the use and interpretation of assays for monitoring autophagy. Autophagy 2012, 8:445-544.

23. Hebron ML, Lonskaya I, Moussa CE: Tyrosine kinase inhibition facilitates autophagic SNCA/alpha-synuclein clearance. Autophagy 2013, 9:1249-1250.

24. Nilsson P, Loganathan K, Sekiguchi M, Matsuba Y, Hui K, Tsubuki S, Tanaka M, Iwata N, Saito T, Saido TC: Abeta secretion and plaque formation depend on autophagy. Cell reports 2013, 5:61-69.

25. Maday S, Wallace KE, Holzbaur EL: Autophagosomes initiate distally and mature during transport toward the cell soma in primary neurons. J Cell Biol 2012, 196:407-417

26. Pacheco CD, Elrick MJ, Lieberman AP: Tau normal function influences Niemann-Pick type $C$ disease pathogenesis in mice and modulates autophagy in NPC1-deficient cells. Autophagy 2009, 5:548-550.

27. Pacheco CD, Elrick MJ, Lieberman AP: Tau deletion exacerbates the phenotype of Niemann-Pick type C mice and implicates autophagy in pathogenesis. Hum Mol Genet 2009, 18:956-965.

28. Hebron ML, Algarzae NK, Lonskaya I, Moussa C: Fractalkine signaling and Tau hyper-phosphorylation are associated with autophagic alterations in lentiviral Tau and Abeta1-42 gene transfer models. Exp Neurol 2014, 251:127-138.

29. Ghazi A, Henis-Korenblit S, Kenyon C: Regulation of Caenorhabditis elegans lifespan by a proteasomal E3 ligase complex. Proc Natl Acad Sci U S A 2007, 104:5947-5952.

30. Simonsen A, Cumming RC, Brech A, Isakson P, Schubert DR, Finley KD: Promoting basal levels of autophagy in the nervous system enhances longevity and oxidant resistance in adult Drosophila. Autophagy 2008, 4:176-184.

31. Korolchuk VI, Mansilla A, Menzies FM, Rubinsztein DC: Autophagy inhibition compromises degradation of ubiquitin-proteasome pathway substrates. Mol Cell 2009, 33:517-527.

32. Bloom GS: Amyloid-beta and Tau: The Trigger and Bullet in Alzheimer Disease Pathogenesis. JAMA Neurol 2014, 71(4):505-508.

33. Congdon EE, Wu JW, Myeku N, Figueroa YH, Herman M, Marinec PS Gestwicki JE, Dickey CA, Yu WH, Duff KE: Methylthioninium chloride (methylene blue) induces autophagy and attenuates tauopathy in vitro and in vivo. Autophagy 2012, 8:609-622.

34. Kruger U, Wang Y, Kumar S, Mandelkow EM: Autophagic degradation of tau in primary neurons and its enhancement by trehalose. Neurobiol Aging 2012, 33:2291-2305.

35. Rodriguez-Navarro JA, Rodriguez L, Casarejos MJ, Solano RM, Gomez A, Perucho J, Cuervo AM, Garcia de Yebenes J, Mena MA: Trehalose ameliorates dopaminergic and tau pathology in parkin deleted/tau overexpressing mice through autophagy activation. Neurobiol Dis 2010, 39:423-438
36. Schaeffer V, Lavenir I, Ozcelik S, Tolnay M, Winkler DT, Goedert M: Stimulation of autophagy reduces neurodegeneration in a mouse model of human tauopathy. Brain 2012, 135:2169-2177.

37. Hebron ML, Lonskaya I, Moussa CE: Nilotinib reverses loss of dopamine neurons and improves motor behavior via autophagic degradation of alpha-synuclein in Parkinson's disease models. Hum Mol Genet 2013, 22:3315-3328.

38. Marzella L, Ahlberg J, Glaumann H: Isolation of autophagic vacuoles from rat liver: morphological and biochemical characterization. J Cell Biol 1982, 93:144-154.

doi:10.1186/1750-1326-9-46

Cite this article as: Lonskaya et al:: Tau deletion impairs intracellular $\beta$-amyloid-42 clearance and leads to more extracellular plaque deposition in gene transfer models. Molecular Neurodegeneration 2014 9:46.

\section{Submit your next manuscript to BioMed Central and take full advantage of:}

- Convenient online submission

- Thorough peer review

- No space constraints or color figure charges

- Immediate publication on acceptance

- Inclusion in PubMed, CAS, Scopus and Google Scholar

- Research which is freely available for redistribution

Submit your manuscript at www.biomedcentral.com/submit
C BioMed Central 